\title{
Designing a Scale to Assess Breastfeeding Support among Public Health Nurses in Japan
}

\author{
Noriko Toyama',2, Kayoko Kurihara', Mineko Muranaka ${ }^{3}$, Kokoro Shirai ${ }^{4}$, Kiyoko Kamibeppu' \\ ${ }^{1}$ Department of Family Nursing, Graduate School of Medicine, The University of Tokyo, Tokyo, Japan \\ ${ }^{2}$ Department of Global Health, Graduate School of Health Sciences, University of the Ryukyus, Okinawa, Japan \\ ${ }_{3}^{3}$ Japanese Nursing Association, Tokyo, Japan \\ ${ }^{4}$ Department of Human Sciences, Faculty of Law and Letters, University of the Ryukyus, Okinawa, Japan \\ Email: norikotoyama@nifty.com
}

How to cite this paper: Toyama, N., Kurihara, K., Muranaka, M., Shirai, K. and Kamibeppu, K. (2017) Designing a Scale to Assess Breastfeeding Support among Public Health Nurses in Japan. Health, 9, 964-974. https://doi.org/10.4236/health.2017.96069

Received: April 15, 2017

Accepted: June 27, 2017

Published: June 30, 2017

Copyright $\odot 2017$ by authors and Scientific Research Publishing Inc. This work is licensed under the Creative Commons Attribution International License (CC BY 4.0).

http://creativecommons.org/licenses/by/4.0/

\begin{abstract}
Background: Promoting breastfeeding support by public health nurses (PHN) requires first that the support which they currently provide to be assessed. However, there is no assessment tool for this purpose. The aim of this study was therefore to develop a scale to assess breastfeeding support currently provided by PHN. Methods: We developed the Practice of Breastfeeding Support Scale (PBSS) for PHN based on the results of a previous study. The content validity of the PBSS was established through discussion with three other researchers. A pilot study was conducted to confirm face validity. To confirm reliability and validity, an anonymous, self-reported questionnaire was sent to PHN working in municipal offices. The statistical analyses included the Kaiser- Meyer-Olkin (KMO), Barlett's Test of Sphericity, exploratory factor analysis (EFA), Cronbach's alpha and correlation coefficient. Results: 768 PHN participated in this study. Cronbach's alpha of PBSS was 0.85. The KMO measure was 0.892, and Bartlett's Test of Sphericity was $\mathrm{p}<0.01$. Three factors together accounted for $59.3 \%$ of the variance in EFA. Construct validity was confirmed through comparison with categories from a previous study. The correlation coefficient of PBSS and Self-efficacy of Breastfeeding Support Scale were $r=0.56(p<0.01)$. PBSS comprised 15 questions and three factors including "Collecting information and assessment," "Direct and individual support," and "Support for group and community." Conclusion: The reliability and validity of PBSS were confirmed. These findings suggested that the PBSS has the potential to help promote breastfeeding support by PHN by clarifying their current breastfeeding support practices and related factors.
\end{abstract}

\section{Keywords}

Public Health Nurse, Breastfeeding Support, Designing Scale 


\section{Introduction}

A meta-analysis recently indicated that breastfeeding conferred protection against childhood infections and malocclusion, increased intelligence, and probably reduced overweight and diabetes [1]. For nursing women, breastfeeding conferred protection against breast cancer, improved birth spacing, and possibly also conferred protection against ovarian cancer and type 2 diabetes. WHO and UNICEF jointly developed the Global Strategy for Infant and Young Child Feeding with the aim of improving the nutritional status, growth, development, health, and thus the very survival, of infants and young children [2]. This strategy promoted improving access to skilled support for initiating and sustaining exclusive breastfeeding for six months.

The breastfeeding rate for 1- to 2-month-old babies was $70.5 \%$ in 1960 , but dropped to $31.7 \%$ in 1970 and had remained low ever since in Japan [3]. However, after breastfeeding began to be promoted from 2000 in a national campaign dubbed, "Healthy Parents and Children 21" and the Guide for Feeding and Weaning Infants and Young Children were published in 2007 [4]; the breastfeeding rate for 1-month-old babies increased by $51.3 \%$ in 2015 [5]. This result also showed that $96 \%$ of mothers surveyed before childbirth were favorably disposed to breastfeeding while $77.8 \%$ of mothers experienced some uncertainty concerning breastfeeding after the birth of their child, especially in not knowing whether their breastmilk was sufficient for their babies.

Several studies showed that mothers were worried about breastfeeding after childbirth [6] [7] and that the breastfeeding rate decreased at one month after childbirth [8] [9]. These findings suggested that follow up was necessary after the mothers were discharged from the childbirth facility [10] [11] [12]. Previous studies reported that support from health workers positively influenced breastfeeding behavior [13] [14] [15]. On the other hand, other studies reported that mothers became nervous or felt ill at ease on receiving authoritarian instructions on breastfeeding from supporters or on observing their negative reaction to mothers who did not make an effort to breastfeed their child [16] [17]. Needless to say, health workers should show sensitivity to mothers when interacting with them in the capacity of a supporter.

Breastfeeding support in Japan is provided at health care facilities and municipalities where mothers receive antenatal checkups, group or individual health education, and undergo delivery. Breastfeeding support is also provided by health workers at the mothers' home or at peer support group activities. Public health nurses (PHN), who work at municipal offices, are among the health workers providing breastfeeding support through group or individual health education and home visits. The PHN's activities reportedly have both positive and negative influences on breastfeeding [18] [19]. Previous studies have shown that the role of the PHN in encouraging/facilitating breastfeeding fell into four categories including "Collecting information", "Assessment", "Direct and individual support", and "Support for group and community", which were further divided into fifteen subcategories including "Infant's condition", "Mother's con- 
dition", "Mother-infant relationship", "Child rearing environment", "Mother's state-of-mind", "Identifying necessary support", "Psychological support", "Concrete support", "Breastfeeding on demand", "Necessary information", "Advice to supporters", "Introducing services", "Breastfeeding-friendly environment", "Breastfeeding support groups", and "Cooperation with relevant organization" [20]. These categories were carefully vetted by a panel of experts who based their assessments on the relevant announcements of the Ministry of Health, Labour and Welfare of Japan [21] and research in public health nursing [22].

Promoting breastfeeding support by PHN requires first that the support they currently provide be accurately assessed. However, there is as yet no tool for this purpose. The aim of this study was, therefore, to develop a scale to assess current breastfeeding support by PHN.

\section{Method}

\subsection{Study Design}

We developed a Practice of Breastfeeding Support Scale (PBSS) questionnaire for PHN based on the results of a previous study [20]. The PBSS questionnaire comprised fifteen questions with four categories including "Collecting information", "Assessment", "Direct and individual support", and "Support for group and community." A likert scale ranging from 1 (never do) to 5 (always do) was chosen for its ease of use not only for the assessors but also for the respondents. The content validity of PBSS was established through discussion with three other researchers, two of whom provided family health nursing and one of whom had more than ten years' experience as a municipal PHN. A pilot study was conducted to confirm face validity.

To confirm reliability and validity, an anonymous self-reported questionnaire, a letter explaining the study, the instructions, and a return envelope were sent to the directors of maternal and child health $(\mathrm{MCH})$ divisions in all municipalities throughout Japan, who were requested to select one PHN as a respondent. The PHNs then returned the completed questionnaires to the researchers.

\subsection{Participants}

PHN working at municipal offices participated in this study. Though PHNs work at several divisions in municipal office, for example $\mathrm{MCH}$, health promotion, mental health and long term care for elderly, only PHN working for $\mathrm{MCH}$ services were selected because breastfeeding support should be provided from them. To control for potential confounders, PHN without midwife qualifications and those who had five to 15 years of working experience were included. If no PHN in a given municipality met these conditions, a PHN with comparable working experience was recruited.

\subsection{Data Analysis}

SPSS version 23 for Windows was used. The Kaiser-Meyer-Olkin (KMO) measure was used for sampling adequacy (using a cut-off of 0.5), and Barlett's Test of 
Sphericity (using a cut-off $\mathrm{P}<0.01$ ) was used to ensure the appropriateness of the data set for exploratory factor analysis. To find the factor structure, factor analysis (principal factor method, promax rotation) was conducted. Cronbach's alpha was calculated to examine the reliability of the scale. Spearman's correlation coefficient was calculated for the PBSS and the Self-efficacy of Breastfeeding Support Scale (SBSS) total scores to confirm criterion-related validity [23]. The statistics for each variable were calculated to delineate more clearly the current breastfeeding support practices provided by PHN.

\subsection{Ethical Approval}

Ethical approval was obtained from the ethical review board of the Faculty of Medicine of The University of Tokyo (Clearance No. 3035).

\section{Results}

\subsection{Characteristics of the Participants}

Of the 1750 questionnaires sent, 831 were returned (response rate: $47.5 \%$ ). Sixty-three were excluded from analysis due to missing data. Therefore the valid response rate was $43.9 \%$ (768). Table 1 shows that $99.7 \%$ of the respondents were female, and that the average age was 35.5 years $(S D=6.2$, range: $22-62)$. The average length of work experience was 10.7 years $(\mathrm{SD}=5.5$, range: 0 - 33). Educational background consisted of vocational school (52.1\%), junior college (17.1\%), university (29.8\%), and graduate School (1.0\%). Participants with personal childbirth experience constituted $65 \%$ of the respondents. Participants

Table 1. Characteristics of participants $(n=768)$.

\begin{tabular}{|c|c|c|c|c|}
\hline & Category & $\mathrm{n}(\%)$ & Average \pm SD & (Range) \\
\hline \multirow[t]{2}{*}{ Sex } & Male & $2(0.3)$ & & \\
\hline & Femal & $766(99.7)$ & & \\
\hline Age & & & $35.5 \pm 6.2$ & $(22-62)$ \\
\hline Working experience & & & $10.7 \pm 5.5$ & $(0-33)$ \\
\hline \multirow[t]{4}{*}{ Final educational } & Vocatinoal school & $400(52.1)$ & & \\
\hline & Junior college & $131(17.1)$ & & \\
\hline & University & $229(29.8)$ & & \\
\hline & Graduate School & $8(1.0)$ & & \\
\hline Childbirth experience & Yes & $499(65.0)$ & & \\
\hline (respondent or their partner) & No & $269(35.0)$ & & \\
\hline Breastfeeding experience & Yes & $496(64.6)$ & & \\
\hline (respondent or their partner) & No & $272(35.4)$ & & \\
\hline Impression of your own & Good & $416(83.9)$ & & \\
\hline breastfeeding experience & Can not say either & $67(13.5)$ & & \\
\hline among person who had & Not good & $10(2.0)$ & & \\
\hline breastfeeding experience & No answer & $3(0.6)$ & & \\
\hline
\end{tabular}


with personal breastfeeding experience constituted $64.6 \%$ of the respondents and included those with partners who participated in some aspect of breastfeeding activity. Of the person who had breastfeeding experience, $83.9 \%$ of participants had good impression of their own breastfeeding experience.

\subsection{Factor Analysis of Breastfeeding Support Practices}

The KMO measure was 0.892 , indicating sampling adequacy. Sufficient variability in the data, confirmed by Barlett's Test of Sphericity $(\mathrm{P}<0.01)$, demonstrated the validity of the data for exploratory factor analysis.

Three factors together accounted for $59.3 \%$ of the variance. No items were excluded because of low loadings (below 0.3). Analysis produced three factors including 15 items (Table 2).

Latent variables were labeled as follows: Factor 1) Collecting Information and Assessment (7 items); Factor 2) Direct and individual support (4 items); and Factor 3) Support for group and community (4 items). The factor contribution was 5.68 for Factor 1, 2.10 for Factor 2 and 1.11 for Factor 3.

Table 2. Factor analysis on practice of breastfeeding support scale (Cronbach $\alpha=0.85)$ ( $n$ $=768$ ).

\begin{tabular}{|c|c|c|c|}
\hline & 1 & 2 & 3 \\
\hline \multicolumn{4}{|c|}{ Factor 1: Collecting Information and Assessment $(\alpha=0.86)$} \\
\hline 1) Infant's condition & 0.93 & -0.28 & -0.01 \\
\hline 2) Mother's condition & 0.93 & -0.16 & 0.02 \\
\hline 4) Child rearing environment & 0.80 & -0.03 & 0.01 \\
\hline 5) Mother's state-of-mind & 0.60 & 0.25 & 0.01 \\
\hline 6) Identifying necessary support & 0.56 & 0.29 & 0.01 \\
\hline 7) Psychological support & 0.75 & 0.09 & 0.03 \\
\hline 8) Concrete support & 0.62 & 0.28 & -0.11 \\
\hline \multicolumn{4}{|l|}{ Factor 2: Direct and individual support $(\alpha=0.74)$} \\
\hline 3) Mother-infant relationship & 0.28 & 0.34 & 0.10 \\
\hline 9) Breastfeeding on demand & 0.06 & 0.79 & -0.14 \\
\hline 10) Necessary information & -0.02 & 0.84 & -0.03 \\
\hline 11) Advice to supporters & -0.19 & 0.83 & 0.10 \\
\hline \multicolumn{4}{|c|}{ Factor 3: Support for group and community $(\alpha=0.70)$} \\
\hline 12) Introducing services & 0.12 & 0.31 & 0.35 \\
\hline 13) Breastfeeding-friendly environment & -0.09 & 0.04 & 0.78 \\
\hline 14) Breastfeeding support groups & 0.00 & -0.01 & 0.84 \\
\hline 15) Cooperation with relevant organization & 0.07 & -0.09 & 0.75 \\
\hline Factor contribution & 5.68 & 2.10 & 1.11 \\
\hline Cumulative contribution ratio (\%) & $37.9 \%$ & $51.9 \%$ & $59.3 \%$ \\
\hline
\end{tabular}

Principal factor method, promax rotation. 


\subsection{Reliability and Validity of the PBSS}

\subsubsection{Internal Consistency}

Cronbach's alpha was calculated to verify the reliability of PBSS. The reliability of PBSS was 0.86 for Factor 1, 0.74 for Factor 2, 0.70 for Factor 3, and 0.85 overall.

\subsubsection{Face Validity}

The participants in the pilot study were 22 PHNs. The results of the pilot study showed that there were no data missing from the questionnaire and no complaints about difficulties in answering the questions.

\subsubsection{Construct Validity}

The three factors resulting from factor analysis were compared with four categories from a previous study on breastfeeding support by PHN: Category 1) Collecting information; Category 2) Assessment; Category 3) Direct and individual support; and Category 4) Support for group and community [20]. Factor 1 included most of the items in Categories 1 and 2, Factor 2 included most of the items in Category 3, and Factor 3 included the items in Category 4. The exceptions were one item from Category 1, "Mother-infant relationship" included in Factor 2; two items from Category 3, "Psychological support" and "Concrete support" included in Factor 1; and 1 item from Category 3, "Introducing services" included in Factor 3.

\subsubsection{Criterion-Related Validity}

Criterion-related validity was assessed by calculating Spearman's correlation coefficient between the PBSS total score and the SBSS total score (Table 3). A significant positive correlation was observed between the PBSS and SBSS $(r=$ $0.56, \mathrm{p}<0.01)$.

\subsection{Practice of Breastfeeding Support}

The mean of the total PBSS was 4.1 (SD \pm 0.4 ; see Table 4). The mean was 4.6 $(\mathrm{SD} \pm 0.4)$ for Factor 1, $4.0( \pm 0.7)$ for Factor 2, and $3.2( \pm 0.7)$ for Factor 3. "Infant's condition" had the highest mean among all the items (M 4.9, $\mathrm{SD} \pm 0.4$ ), and "Breastfeeding-friendly environment" had the lowest mean (M 2.6, SD \pm 1.0).

\section{Discussion}

\subsection{Reliability of the PBSS}

Cronbach's alpha indicated that all factors exceeded the reference value, thereby ensuring the reliability of the scale.

Table 3. The correlation coefficient between the PBSS total score and the SBSS total score $(n=768)$.

\begin{tabular}{ccc}
\hline & $\mathrm{r}$ & $\mathrm{p}$ \\
\hline Spearman's correlation & 0.56 & $<0.01$ \\
\hline
\end{tabular}


Table 4. Practice of breastfeeding support scale for public health nurse $(n=768)$.

\begin{tabular}{lccc}
\hline & Mean & \pm SD & (Range) \\
\hline Factor 1: Collecting information and assessment & 4.6 & \pm 0.4 & $(2-5)$ \\
1) Infant's condition & 4.9 & \pm 0.4 & $(2-5)$ \\
2) Mother's condition & 4.8 & \pm 0.4 & $(2-5)$ \\
4) Child rearing environment & 4.6 & \pm 0.6 & $(2-5)$ \\
5) Mother's state-of-mind & 4.4 & \pm 0.7 & $(2-5)$ \\
6) Identify necessary support & 4.3 & \pm 0.7 & $(2-5)$ \\
7) Psychological support & 4.7 & \pm 0.5 & $(2-5)$ \\
8) Concrete support & 4.6 & \pm 0.7 & $(2-5)$ \\
Factor 2: Direct and individual support & 4.0 & \pm 0.7 & $(2-5)$ \\
3) Mother-infant relationship & 4.3 & \pm 0.8 & $(1-5)$ \\
9) Breastfeeding on demand & 4.2 & \pm 0.8 & $(1-5)$ \\
10) Necessary information & 4.1 & \pm 0.8 & $(1-5)$ \\
11) Advice to supporters & 3.6 & \pm 1.0 & $(1-5)$ \\
Factor 3: Support for group and community & 3.2 & \pm 0.7 & $(1-5)$ \\
12) Introduce services & 4.0 & \pm 0.9 & $(1-5)$ \\
13) Breastfeeding-friendly environment & 2.6 & \pm 1.0 & $(1-5)$ \\
14) Breastfeeding support groups & 3.1 & \pm 1.0 & $(1-5)$ \\
15) Cooperation with relevant organization & 3.1 & \pm 1.1 & $(1-5)$ \\
Average & 4.1 & \pm 0.4 & $(2-5)$ \\
\hline
\end{tabular}

\subsection{Validity of the PBSS}

The validity of the PBSS was assessed in terms of content validity, face validity, construct validity, and criterion-related validity.

\subsubsection{Content Validity of the PBSS}

The PBSS was based on a previous study on breastfeeding support by PHN in Japan, and was revised following a discussion of the pilot study by a panel of experts to ensure content validity.

\subsubsection{Construct Validity of the PBSS}

The construct validity was assessed through a comparison with the categories used in the aforementioned study and the results of exploratory factor analysis. The three factors extracted were almost identical to those of the previous study and indicated construct validity. All items except two including "Mother-infant relationship" and "Introducing services" showed higher factor loadings than the other factors at greater than 0.5 .

The factor loadings for "Mother-infant relationship" were 0.34 for Factor 2 and 0.28 for Factor 1. The factor loadings for "Introducing services" were 0.35 for Factor 3 and 0.31 for Factor 2. These results indicated that the items had a high likelihood of being related to "Direct and individual support" and "Support 
for group and community", respectively. On the other hand, a relationship with other factors was possible; hence the manner in which some of these questions were framed should be reconsidered.

"Psychological support" and "Concrete support" were included in Factor 1. These two factors were categorized into "Direct and individual support" in the previous study although they were closely related to "Collecting information and assessment". Further investigation is necessary to clarify this relationship.

\subsubsection{Criterion-Related Validity.}

A significant positive correlation was observed between the PBSS total score and the SBSS total score demonstrating criterion-related validity for the PBSS.

\subsection{Utilization of PBSS}

The results of the PBSS showed that the score for "Collecting information and assessment" was higher than for other factors. However, the score for "Direct and individual support" was lower than the latter, while the score for "Support for group and community" was lowest among all the factors. In particular, the score for "Breastfeeding-friendly environment" was extremely low, indicating that the PHN did not provide satisfactory support.

A previous study which measured the self-efficacy of breastfeeding support also showed that items related to a breastfeeding-friendly environment, which required policy planning, resource mobilization, and intersectional collaboration to create, had lower average scores than other items [23]. Michibayashi suggested that long work experience as a PHN and post-graduate education were required for competent policy planning including creating projects and mobilizing resources [24]. The results of the present study might be explained by the fact that the participants were relatively young and lack the types of training or experience mentioned above.

\section{Limitations}

One of the limitations of this study lay in the possibility that some of the items may have been related to other factors. Therefore the manner in which some of the questions were framed should be reconsidered for future studies. Also, test-retest reliability was not confirmed in this study. Therefore further study is expected to improve the scale of practice of breastfeeding support for PHN.

\section{Conclusions}

The reliability and validity of the PBSS were confirmed by the results of our analyses. The PBSS comprised 15 questions and three factors including "Collecting information and assessment", "Direct and individual support", and "Support for group and community." The score for "Collecting information and assessment" was higher than for the other factors; on the other hand, the score for "Support for group and community" was lowest among all the factors.

The findings of this study strongly suggested the likelihood that the PBSS 
would be effective in promoting breastfeeding support by PHN by clarifying current breastfeeding support provided by PHN and the factors related to this practice.

\section{Acknowledgements}

We are grateful to the PHNs who took the time to answer the questionnaire. We would like to express our gratitude to the faculty and members of the Department of Family Nursing, Graduate School of Medicine, School of Health Science \& Nursing in the University of Tokyo.

\section{Conflict of Interest}

We declare no conflict of interest.

\section{Source of Funding}

This study was funded by Grants-in-Aid for scientific research expenses of the Ministry of Education, Culture, Sports, Science and Technology (grant number 2139 0589).

\section{Contributions}

Noriko Toyama: study design, data collection, data input, data analysis, discussion, and finalized the manuscript.

Mineko Muranaka: study design, data collection, discussion, and reviewing of the paper.

Kayoko Kurihara: study design, data analysis, discussion, and reviewing of the paper.

Kokoro Shirai: data analysis, discussion, and reviewing of the paper.

Kiyoko Kamibeppu: supervised all the processes involved in this study.

All authors read and approved the final manuscript.

\section{References}

[1] Victora, C.G., Bahl, R., Barros, A.J.D., França, G.V.A., Horton, S., Krasevec, J., Murch, S., Sankar, M.J., Walker, N. and Rollins, N.C. (2016) Breastfeeding in the 21st Century: Epidemiology, Mechanisms, and Lifelong Effect. Lancet, 387, 475-490. https://doi.org/10.1016/S0140-6736(15)01024-7

[2] WHO (2002) Global Strategy for Infant and Young Child Feeding. http://www.who.int/nutrition/publications/gs infant feeding text eng.pdf

[3] Mother's and Children's Health and Welfare Association (2008) Maternal and Child Health Statistics of Japan. Statistics, Mother's and Children's Health and Welfare Association, Tokyo.

[4] Ministry of Health, Labour and Welfare (2007) Guide for Feeding and Weaning Infants and Young Children. http://www.mhlw.go.jp/shingi/2007/03/dl/s0314-17.pdf

[5] Ministry of Health, Labour and Welfare (2016) Result of Young Child Nutrition Survey in 2015.

http://www.mhlw.go.jp/file/06-Seisakujouhou-11900000-Koyoukintoujidoukateikyo ku/0000134460.pdf 
[6] Ueyama, N. and Matsuo, H. (2009) The Evaluation of the Experiences and Coping Behavior in Mothers in Antepartum and Postpartum. Bulletin of Kobe University Department of International Health, 24, 41-50. http://www.lib.kobe-u.ac.jp/repository/81001042.pdf

[7] Karata, N. and Morita, A. (2007) Study on the Concerns of Mothers with Young Children in Chiba Prefecture in Relation to Child-Rearing: Focusing on Possible Differences among Children's Ages and Mothers' Birth Experience. The Bulletin of the Institute of Human Sciences, 7, 249-263.

[8] Teramae, M., Yoshida, A. and Tanaka, K. (1996) Study on Factor Influencing Breastfeeding of 3 - 4 Month Old Baby in This Hospital. Japanese Nursing Society, 27, 139-142.

[9] Go, K., Onoue, E. and Nishiyama, K. (2005) Examination of the Necessity of Our Help for Mothers Continuing Breastfeeding by Mother after Delivery in Nuclear Family. Journal of Fukushima Rural Medicine, 47, 57-59.

[10] Ishiguro, K., Kiyokawa, K. and Nakao, T. (2008) Background and Practice of Breastfeeding Promotion at Juzo Civil Hospital. Journal of Kinki Newborn Study Association, 17, 51-54.

[11] Braun, M.L., Giugliani, E.R., SOares, M.E., Giugliani, C., de Oliveira, A.P. and Danelon, C.M. (2003) Evaluation of the Impact of the Baby-Friendly Hospital Initiative on Rates of Breastfeeding. American Journal of Public Health, 93, 1277-1279. https://doi.org/10.2105/AJPH.93.8.1277

[12] Coutinho, S.B., de Lira, P.I., de Carvalho, L.M. and Ashworth, A. (2005) Comparison of the Effect of Two Systems for the Promotion of Exclusive Breastfeeding. Lancet, 266, 1094-1100. https://doi.org/10.1016/S0140-6736(05)67421-1

[13] de Jager, E., Broadbent, J., Fuller-Tyszkiewicz, M., Nagle, C., McPhie, S. and Skouteris, H. (2015) A Longitudinal Study of the Effect of Psychosocial Factors on Exclusive Breastfeeding Duration. Midwifery, 31, 103-111. https://doi.org/10.1016/j.midw.2014.06.009

[14] Zhu, J., Chan, W.C., Zhou, X., Ye, B. and He, H.G. (2014) Predictors of Breast Feeding Self-Efficacy among Chinese Mothers-A Cross-Sectional Questionnaire Survey. Midwifery, 30, 705-711. https://doi.org/10.1016/j.midw.2013.12.008

[15] Abbass-Dick, J., Stern, S.B., Nelson, L.E., Watson, W. and Dennis, C.L. (2015) Coparenting Breastfeeding Support and Exclusive Breastfeeding-A Randomized Controlled Trial. Pediatrics, 135, 102-110.

[16] Hongo, H. (2002) Supporting Mother Who Experienced Breastfeeding Difficulty for Her First Baby. Journal of Midwifery, 56, 540-545.

[17] Watanabe, H. (1996) Current Clinical Practice of Mother and Child. Science of the Mind, 66, 16-21.

[18] Kronborg, H., Vaeth, M., Olsen J. and Harder I. (2008) Health Visitors and Breastfeeding Support: Influence of Knowledge and Self-Efficacy. European Journal of Public Health, 18, 283-288. https://doi.org/10.1093/eurpub/ckm121

[19] Hiraiwa, M. (2009) Physical Development for Infant. Journal of Public Health, 73, 783-786.

[20] Toyama, N., Muranaka, M., Kurihara, K. and Kamibeppu, K. (2017) Qualitative Study of Breastfeeding Support by Public Health Nurses in Japan. Health, 9, 451-458. https://doi.org/10.4236/health.2017.93032

[21] Ministry of Health, Labour and Welfare (2013) About Activities of Public Health Nurse at the Community. http://www.nacphn.jp/topics/pdf/2013 shishin.pdf

[22] Hirano, K. (2000) Prospective of Public Health Nursing. Research on Public Health, 
49, 116-124.

[23] Toyama, N., Muranaka, M., Kurihara, K. and Kamibeppu, K. (2013) Factors Influencing Self-Efficacy in Breastfeeding Support among Public Health Nurses in Japan. Health, 5, 2051-2058. https://doi.org/10.4236/health.2013.512278

[24] Michibayashi, C., Kobayashi, K. and Ishihara, T. (2017) Correlation between Competencies and Difficulties Related to the Creation of Projects/Social Resources for Local Government-Based Public Health Nurses in Mid- and Late-Levels. Japanese Journal of Health and Human Ecology, 83, 13-25.

https://doi.org/10.3861/jshhe.83.13

Submit or recommend next manuscript to SCIRP and we will provide best service for you:

Accepting pre-submission inquiries through Email, Facebook, LinkedIn, Twitter, etc. A wide selection of journals (inclusive of 9 subjects, more than 200 journals) Providing 24-hour high-quality service User-friendly online submission system Fair and swift peer-review system Efficient typesetting and proofreading procedure Display of the result of downloads and visits, as well as the number of cited articles Maximum dissemination of your research work

Submit your manuscript at: http://papersubmission.scirp.org/ Or contact health@scirp.org 